\title{
The place of medicine in the American prison: Ethical issues in the treatment of offenders
}

\author{
Peter L Sissons The Department of Sociology, Fordham University, Bronx, New York
}

In Britain doctors and others concerned with the treatment of offenders in prison may consult the Butler Report (see Focus, pp 157) and specialist journals, but these sources are concerned with the system in Britain only. In America the situation is different, both in organization and in certain attitudes. Dr Peter $L$ Sissons has therefore provided a companion article to that of Dr Paul Bowden (page 163) describing the various medical issues in prisons.

The main difference between the treatment of offenders in prisons in America and in Britain lies in the nature of the federal system which means that each state may operate a different system in a variety of prisons and prison medical services are as various. Nationally, the prison systems are 'structured to treat and cure the offender'. Therefore it follows that the prison medical officer is only one of the professionals concerned with this 'cure' of the offender. This principle also applies to any form of research: medical research in prisons is part of a programme which covers a wide field of social and judicial research. The prison medical officer (where there is one) has of course to look after sick prisoners, and the American idea of 'cure' is also expressed in the need for more corrective surgery where, for example, it is necessary to remove physical impediments to social rehabilitation. But a doctor is only found on the staff of those institutions which are large: in the smaller prisons there may be only first-aid facilities, and no specially appointed doctor in the community. Moreover medicines are often dispensed by medical auxiliaries who are sometimes prisoners themselves. Finally, in America prisoners are regularly invited to volunteer as subjects for medical and social research for which they are paid. In short, although it is hoped to 'cure' a prisoner he is a criminal first and a patient second.

The medical professions have not been exempt from the accusations generated by the unrest in American prisons during the last decade. Criticism of inadequate medical services in many correctional institutions and the ethical practices of some prison doctors and medical researchers have not been confined to the emotive exposés of former prison wardens and books such as Jessica Mitford's Kind and Usual Punishment (1973). It has shaped the content of Congressional debates, informed the evidence presented before Senate subcommittees and pro- $\overrightarrow{0}$ vided the focus for investigations conducted by $\overrightarrow{\vec{H}}$ government select committees and associations of $\omega_{\mathrm{o}}$ the legal and medical professions.

While the accusations are most often expressed as indictments of the philosophy and management $N$ of correctional systems, they point to a number of underlying issues concerning the social functions of $\omega$ medicine and the role of medical professionals within $ᄋ$ a penal system. It will be argued in this paper that in order to understand the ethical dilemmas of $D$ medical science in relation to the incarcerated ${ }_{\infty}^{\infty}$ offender, it is necessary to examine them within the $\frac{\mathbb{}}{3}$ context of the dominant penal philosophies which $\frac{\nabla}{\mathbb{N}}$ inform the various correctional systems in the United States. It will also be argued that the political $\vec{\theta}$ tendency to distil ethical judgments from individual \% issues as they separately emerge has resulted in a failure to recognize the ethical problems which underly the interrelatedness of such issues.

This paper will attempt to bring together three

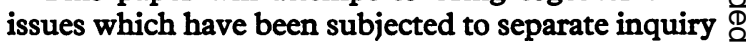
in the United States during recent years. They are: $\overrightarrow{\vec{A}}$ I) the delivery of medical services to prison in- $\frac{3}{3}$ mates, 2) therapeutic medical research conducted upon individual inmates, and 3) non-therapeutic medical research conducted upon selected populations of prisoners. An attempt will be made to show how an examination of these issues raises questions $\frac{0}{3}$ concerning the involvement of medical ethics not only in issues of human rights but also in the deter- $\delta$ mination of priorities in the relationship between $₹$ medicine and other disciplines which purport to $\frac{9}{5}$ operate on a 'medical model' of social organization. $>$ It will be argued that a key problem confronting the prison doctor and those responsible for the organization of prison medical services goes beyond the $\sigma$ ordering of priorities within medicine to the $N$ ordering of priorities between medical and other $\underset{\mathrm{W}}{N}$ modes of treating inmates. It will be further argued ${ }_{0}$ that the apparently humanistic position of treating 0 the inmate for purposes of rehabilitation has been $\frac{D}{\mathbb{D}}$ the source of the ambiguity and conflict which have $\stackrel{?}{?}$ contributed to the substandard medical procedures $T$ present in many American correctional institutions.

\section{The medical model of the prison}

The imprisonment of offenders in the United States occurs at each of the three main levels of criminal 
justice - the federal, the state and the local. At each level relatively autonomous correctional systems are maintained, providing for considerable diversity in institutional and organizational structure as well as in the type and number of offenders.

The United States Bureau of Prisons is responsible for maintaining 43 federal correctional institutions which accommodate 23000 prisoners. Comparably accurate figures are unavailable for the correctional systems in the 50 states. It was estimated in 1973, however, that about 190000 adults were serving sentences in the state prison systems and in the District of Columbia and Puerto Rico (Carter et al, 1975). Operated variously by state, county and city governments, there are more than 4000 local jails which are occupied by the accused awaiting judicial disposition, minor offenders serving sentences up to one year in duration, and a relatively small number of felons who in extreme instances may be serving sentences which are as long as 99 years. According to the only nation-wide jail census ever made, there were $16 \mathrm{r} 000$ persons confined in local jails in March 1970. It has been estimated that more than three million accused individuals are admitted to all the nation's jails in any given year (US Law Enforcement Assistance Administration and US Bureau of the Census, 1973).

The enormity of these systems with their thousands of institutions and their constantly changing populations creates extraordinary difficulties for those who attempt either to separate or to generalize about specific problems arising within the prison. The systems and the institutions which constitute them are characterized by diverse and often conflicting philosophies which are embodied in their organizational structures and objectives. Inevitably they experience correspondingly different problems - economically, administratively and programmatically. This is no less true for the provision of medical services and the application of medical science to correctional problems than it is for the provision of custodial arrangements or educational programmes.

Although subject to increasing scepticism, the dominant philosophy in the American prison systems since the nineteenth century has been based on the positivist understanding of crime as a form of sickness. While residual elements of all the historical schools of criminology are juxtaposed within the several systems, it is the notion of crime as individual or social pathology which is most commonly articulated by the several criminal justice administrations. Ostensibly, and with few exceptions, the prison systems are structured to treat and to 'cure' the offender. While different opinions concerning the nature of the pathology and the appropriate modes of treatment result in differing institutional emphases, it is this broad understanding of crime with its influence upon the structure and operation of the correctional institution which produces the medical model of the prison. Within such a model medical treatment is just one additional form of

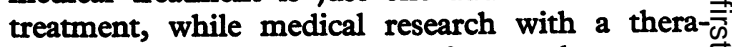
peutic goal is only one form of research among of multiplicity of therapy-motivated research pro-등 grammes. The medical professional, although $\overline{\frac{\bar{p}}{2}}$ providing a model for the role of many of the crimi- $-\mathbb{\Phi}$ nal justice professions, is just one specialist working alongside others from many disciplines who, whatever their specialization, are pursuing a com $-\overrightarrow{0}$ mon goal, the reform of the imprisoned offender.

\section{Medical services in the medical model}

The standards established by the professional associations of the correctional professions acknowledge that the provision of medical services is anct essential component of the individual prisoner'so rehabilitation programme. The Manual of Cor-rectional Standards (1969), published by the American Correctional Association, and the Manual of Fail Administration (1970), published by thes National Sheriffs' Association, both emphasize the role of medical services in the treatment of. the inmate as an offender. Generally accepted as the norms for prison administration, the American? Correctional Association standards stress three things. First, every prisoner who has a remediables physical condition should be provided with the medical or surgical services which would restore himb to the fullest measure of health possible before release from the institution. Secondly, physical defects which might interfere with rehabilitative success either5 because of their psychological impact upon the? prisoner or because they interfere with futurect. employment, should be subject to a 'correctionat surgical programme'. Such a programme goeso beyond the correction of physical disablement which? might functionally interfere with employment, to include the elimination of stigmata which mighto stereotype an individual as a criminal. One student of the American system has observed that 'cosmetic? and plastic surgery is more important in prison and juvenile institutions than any place else. There are crossed eyes that need to be straightened. There aren prominent facial scars, including gunshot wounds; that need to be removed. There are many dis $N$ figurements, both congenital and the results oftw fights and accidents, that need to be removed' (Fox, 1972). Thirdly, the standards endorse the sociab esteem of the medical profession by approving itsर्ण contribution to the understanding and explanation? of criminal behaviour and by stressing that the fieldo of corrections provides a valuable career opportunity for the physician because 'the practice of medicine in penal institutions affords unique opportunities to gain increased understanding ofomedical psychology, to improve administrative skills and to participate in behavioural research'. 


\section{HIGH INCIDENCE OF SICKNESS IN PRISONERS}

Disregarding the more controversial biogenetic theories of criminal behaviour, there is undoubted evidence of an unusually high incidence of medical sickness among convicted offenders. It has been estimated that 95 per cent of the inmates received by the federal prison system require immediate medical care for preexisting conditions (Alexander, 1972). While the larger prisons have their own hospital facilities and the jails and smaller prisons use hospitals in the community, which in some instances are equipped with prison wards, the Federal Bureau of Prisons and a number of states maintain separate institutions equipped as hospitals which sometimes make special provisions in a custodial setting for the chronically ill offender, the aged, the 'criminally insane' and the sexually dangerous. Such institutions alone have an average annual population of about 10 000 .

If the physical examination of newly admitted inmates reveals a substantial need for the provision of medical services in the prison systems, at least one study has suggested that even where those services are available the health of the inmate is more likely to deteriorate inside a correctional institution than it is outside. The worsening of mental health conditions, high incidences of chronic digestive ailments and wounds inflicted by fights and assault distinguished a sample of inmates of the Tennessee State Penitentiary from a sample of offenders supervised in the community by the state probation department (Jones, 1975).

Studies sponsored by the American Bar Association, the American Medical Association and select committees of various state assemblies have revealed that the manual of correctional standards notwithstanding, the provision of medical services in state institutions and jails has a low priority. Most states, according to one study, were reluctant to spend money on facilities and equipment, while the salaries of prison physicians were demonstrably lower than those received by their colleagues working in the community (Alexander, 1972). An investigation of medical practice within the California Department of Correction revealed the employment of medical auxiliaries to conduct the initial and invariably the only examination at sick call (California Assembly Select Committee on Prison Reform and Rehabilitation, 1972). The American Bar Association's investigation conducted in 1972 reported an inability on the part of physicians to achieve rapport with inmates, while the California investigation produced accusations that the physicians showed a lack of concern for their inmate patients.

The jails seemingly present an even more critical problem. In a survey of almost 3000 local jails sponsored by the American Medical Association and the American Bar Association, 65.5 per cent had only first-aid facilities while 78 per cent had no formal arrangements with physicians in the community for the provision of medical care (American Medical Association, 1972; American Bar Association, Resource Centre on Correctional Law and Legal Services, I973; MD, 1974). The study also found that in more than 80 per cent of the jails, medicines are dispensed by non-medical personnel. The observations of one former prison superintendent suggest that some prisoner medical auxiliaries exploit this situation by selling medicines to other prisoners and by controlling access to the prison doctors as a part of the prison barter system (Murton, I972).

BTHICAL DILEMMAS IN THE MEDICAL MODEL

The ethical issue most commonly identified with the provision of medical services to the inmate is the question of interference with the prisoner's right to treatment, no matter what his offence. But within the medical model, the ethical dilemma involved is more complex than one of mere exploitation on the part of the medical or paramedical staff. The root cause of poor medical treatment in the prison is not solely a result of deliberate misuse or the withholding of adequate services, it is often the result of a difficult question of priorities. The doctor is only one part of the treatment staff and he must share resources with other professionals whose treatment of the inmate may be more beneficial than his. If resources for medical services and physicians' salaries are limited, so also are the resources for vocational training, education, psychological counselling and custodial needs. The competitive situation of medical services within the prison system is rendered ambiguous, however, by the fundamental confusion which exists between the provision of medical care for an inmate who is suffering from a physical complaint and the function of medicine in relation to the criminal when crime is identified as individual pathology.

The role of the doctor in the prison differs from the role of the doctor employed in other nonmedical institutions. It would be hard to conceive of a medical model of an army or an automobile company. In the army or industry, the doctor serves the needs of the organization by ensuring the fitness of its members to achieve organizational efficiency. In such situations, the doctor may be deferred to by the organization; medical opinion is respected because it furthers the ends of the organization. In the medical model of the prison, the institution exists to achieve a cure for its patients. Unlike a prison system which is unambiguously based on punishment where the doctor's responsibility to the institution is that of simply providing medical care for his captive patient, in the medical model the role of the doctor is not radically dissimilar from that of his colleagues on the treatment staff of the prison. If the doctor shares the percep, 
tion of the inmate as being intrinsically sick by virtue of his criminality, then he has to measure his diagnoses and treatment against the value of nonmedical diagnoses and treatment in the interests of his patient. How is the prison doctor to distinguish the treatment of illness from the treatment of crime and to which must he give priority ? If the prison doctor is identified as being a part of the prison's treatment team, must the specialist treatment for which he is responsible periodically yield priority to some alternative non-medical treatment with all that entails in terms of budgets and the provision of facilities? By what mechanisms and informed by what values are the decisions concerning priorities between the treatment sciences to be made, and who has the responsibility for making them ?

If the prison physician sees himself to be part of a team engaged in treating the pathology of crime he must demonstrate that he is in fact treating crime no less than his non-medical colleagues. Robert Merton has suggested that there are three bases of medical advice (Merton, 1973): empiricism, in which the prescribed treatment is based upon the experience of the doctor in both diagnosis and prescription; standardized therapies derived from cumulative medical research; and advice based on specific medical research orientated towards obtaining solutions for newly discovered problems. It is in the first and the last of these, empiricism and new research, that attempts to treat the medical manifestations and causes of crime occur.

In the case of empiricism, the employment of prisoners as medical auxiliaries and non-medical personnel in the provision of medical care, along with an acceptance of stereotypes by the prison doctor, are expressions of experiential responses to the innate criminality of the imprisoned patient. The identification of minor ailments as evidence of evasion, and the use of medical care as a form of barter by the inmates are indicators that the ailing prisoner is regarded as a criminal first and a patient second. This is no less true in the area of specific research orientated towards new problems where biomedical and neurological researchers have continuously attempted to explore the medical sources of criminal behaviour and to seek for corresponding cures.

\section{Therapeutic research upon prisoners}

It is in the fields of psychiatry and neurology particularly that the quest for the medical sources of criminality occurs and the ethical issues of therapeutic research conducted upon either voluntary or involuntary human subjects are raised. It is in these areas particularly that the distinction between research and treatment has been conveniently blurred.

Therapeutic prison research has been described as being investigation into the presumed causes of medical, psychiatric, psychological or criminological abnormalities believed to be responsible for anti-social behaviour ... although it is possible that the individual participant may be helped, $i \vec{E}_{\text {D }}^{*}$ is ordinarily anticipated that experimental results will benefit similarly situated patients in the future $\frac{t}{O}$ (Todd, 1975).

The quest for physiological and psychiatriç explanations of criminal behaviour has continueof almost unabated since the conclusion by the nines teenth century Italian physician Lombroso tha $\vec{b}$ criminality was a congenital condition. While earlier modes of explanation such as atavism, soma totypology and phrenology have been largely reduced to the status of myth, genetic theories, chromosomal imbalance and brain malfunction continue to receive some controversial credence: The major ethical dilemma generated by research experiments based upon such theories is that the experiments, consciously or unconsciously, may be disguised as treatment. The debates around this issue in the American courts and in Congress have focused upon two questions: At what point is compulsory experimental treatment ethically justio fied in the case of criminals ? and how justifiable is it to make experimental treatment voluntarilse available?

In the United States such ethical issues have become legal issues as a series of 'right to treatment cases have been heard by state courts. The judiciary has been criticized because of its reluctance tof recognize completely the right of the prison inmate to receive certain forms of treatment, including in one famous instance in Detroit, the right of a sex offender to undergo voluntary brain surgery which he was assured would reduce his sexuaț aggressiveness. Whatever its legal merits, case law has proved itself to be peculiarly unwieldy for decid ing on the complex ethical issues which have been raised by the application of therapeutic medica? research to individuals in confinement. In this the courts mirror the confusion within the medicaR profession, a confusion which is an expression of the uncertainty which surrounds the aetiology of crime. Does the convicted offender have a lega? right to rehabilitation (Kassirer, 1974) ? If he does N how might a distinction be made between medicaP rehabilitative treatment and medical experiment 50 Does enforced treatment violate an inmate's right\& to due process and equal protection of the law, and therefore constitute "cruel and unusual punisho ment'?

The decisions by the courts are confusing and? also contradictory. In some states the absence of facilities for the mandatory treatment of offenders who are drug addicts has been interpreted as crueb and unusual punishment, for example, while ins other states the forced participation of inmates in rehabilitation programmes was ruled to violate due process. On the whole the courts do not dis음 
tinguish between medical and other forms of treatment of prisoners. It is the prisoners' rights rather than the validity of the treatment which are the subjects of court decisions. Does the prisoner have the right to refuse treatment? Does the prisoner have the right to demand treatment ? If the prisoner has the right of choice, does he have sufficient information available to him in order that he might exercise full freedom of choice ?

Seeking to determine if new medical advances require legislation to resolve many of the ethical questions which they pose, the Senate Health Sub-Committee, under the chairmanship of Senator Edward Kennedy, began to address itself to some of the unresolved questions raised by the relationship between treatment and experimental research. Discussing the implications of neurosurgery before the Senate, Senator Kennedy posed the question which medical ethics has not addressed in relation to experimental treatment: '... can any prisoner who is in an inherently coercive situation really volunteer for anything?' (Congressional Record, August, 1972).

\section{Non-therapeutic research on prisoners}

The debate on therapeutic medical experimentation overlaps the even more controversial issues which surround the practice of non-therapeutic medical research in prisons. Unlike Great Britain where legislation prohibits the conduct of biomedical experiments on inmate populations, most of the early testing of new drugs in the United States is done in prisons. The ethical issues concerning the freedom of an inmate to volunteer to participate in a medical experiment, which is unrelated to his condition, parallel those concerning the right of the inmate to receive treatment. In both cases the issue focuses upon how informed the inmate may be concerning the nature of what he is actually volunteering for.

Many of the objections to an inmate's participation in volunteer research programmes raised by human rights groups argue that the inmate is in no position to inform himself of the potential harm to which he may be subject as a result of his participation, nor is he able to evaluate the advantages and disadvantages of his participation. The conditions of his confinement and the lure of even modest financial rewards might weigh inappropriately in his decision to participate in a research programme which may subject him to physical discomfort and possibly physical impairment without the reasonable assurances of a therapeutic result. The pharmaceutical companies have been criticized for unfairly taking advantage of the psychological conditions of being imprisoned in order to accrue considerable savings on the cost of their legally required experiments. This economic exploitation of prisoners has provided one of the major platforms for the condemnation of the drug companies and the doc- tors who facilitate the experiments. The payment to the inmate for his services to the pharmaceutical industry may be as low as one tenth the amount demanded by non-prisoners. It is estimated that this low level of reimbursement, coupled with the obligations of the correctional institutions to provide food, clothing and housing for their inmates, has provided the pharmaceutical companies with a subsidy of the minimum equivalent of $\$ 26.05$ a subject day, a subsidy which amounts to millions of dollars annually (Meyer, 1975).

Notwithstanding the negative implications of prisoners' involvement in biomedical experiments, it is estimated that prisoners are five times more likely to volunteer for participation in research than anyone else, and inmates have been prominent in attempts to resist legislation prohibiting medical experiments in prisons.

If therapeutic medical research is sometimes sufficiently experimental in nature to justify questions concerning its value for the experimental patient, non-therapeutic research may have an ancillary, totally unplanned therapeutic effect upon its subjects. Participation in an outsidesponsored programme which offers financial rewards and psychological contact with the outside world may go some way towards alleviating the pains of imprisonment and improving an inmate's self esteem. This was tacitly recognized 25 years ago when the House of Delegates of the American Medical Association passed a resolution disapproving of the participation of certain kinds of inmates in scientific experiments. Specifically to be excluded from participation were inmates who had been convicted of murder, rape, arson, kidnapping and treason. In part this resolution was based upon the belief that participation in research might result in social esteem acknowledged by the presentation of citations and the granting of early parole (Schwitzgebel, 1968). Medical science might find itself to be in a position of interfering with the normal course of justice for particularly serious offenders.

In the same way that prisoners have gone to court in search of favourable rulings concerning their right to receive or refuse treatment, so also prisoners have protested their right to participate in biomedical experiments. Not only do they see such experimentation as a welcome source of income, they also protest that their participation gives them a sense of involvement in a world beyond the prison, giving meaning to lives which otherwise are bound by the monotonies of prison life. In the latter part of the 1960 s when the Federal government sponsored space research in prisons, studies of the response of human subjects to heat stress, weightlessness and impact, both the prison and national press described prisoners' satisfaction at participation in a programme of national importance. An independent evaluation of a drug company's 
experiments in a Connecticut prison suggested that the experiments had an important rehabilitative effect upon inmates. The participants in the experiments were found to have greater potential for parole success, their involvement in the world beyond the prison was wider, and they were less constrained by the effects of imprisonment (Wells et al, 1975).

In response to the attempts to eliminate totally non-therapeutic experimentation in prison, new standards and guidelines have been proposed by the American Correctional Association (American Correctional Association, 1972) and by independent researchers which are primarily concerned with the implementation of the principles deriving from the military tribunal in Nuremberg, the United States Food and Drug Administration's regulations for research on human subjects and the Helsinki declaration of 1966 (Bowers, 1972). Typically such studies focus upon the issues of the voluntary principle and monetary reward.

A new regulatory approach has been proposed from within the School of Medicine at the University of California. This recommends the establishment of separate risk ratings for medical experiments and their penal settings. The experiments would be rated for their potential physical risk to inmates and the penal settings would be rated for the 'risk of ethical impairment' inherent within their organizational characteristics. Ethical impairment would be assessed in terms of the opportunity available to the inmates for free and informed decision making. Such a model would permit the measurement of the inverse relationship between the levels of physical and ethical risk as the baseline for policy decisions. The greater the constraints upon informed decision making by the prisoner, the lower the physical risk of experiments to be permitted in the institution (Jonsen et al, 1975).

\section{Conclusion}

Medical science interacts with the prison in the three outlined areas of medical care, research with a therapeutic intention and non-therapeutic medical experimentation. Separate ethical judgments are involved in the specific issues of each area, but they are pivotally linked around two fundamental questions. What are the clinical contributions which medicine may make to the treatment of the criminal ? and in what ways are such contributions compatible with prevailing theories of the aetiology of crime? This paper has argued that while the intent of the medical model is humanistic, the failure to distinguish between the sickness of an inmate as manifest by his criminality, and his sickness as manifested in those physical symptoms by which illness is generally diagnosed in the non-criminal population, leads to confusion concerning the functions of medicine within the prison. The result of this confusion is ambiguity in the ethical norms which underly medical practice within the prison.

If the doctor is expected to give priority to the treatment of criminality, then there may be good reason for his treatment periodically to yieles priority to other treatment programmes such as education or job training. This is particularly the case if the cause of crime is presumed to lie in socialo psychological and other non-medical areas. On the्t other hand, if the aetiology of crime is presumed to be rooted in genetic or biological causes, the ethical imperatives upon the doctor are to provid $\overrightarrow{\mathrm{e}_{\text {}}}$ medical treatment for criminality itself and to carrs out therapeutic research in order to provide more effective treatment for the pathology of crime in the future.

The issue is further complicated in relation tô biomedical and other research carried out for somet social purpose and to which the inmate is cons tributing by volunteering as a subject. Evidencesuggests that such research may have an immediate therapeutic effect which possibly exceeds that of directly intended therapeutic research. The medicas profession, therefore, is faced with the question of whether using prisoners to contribute to medical projects not set up directly for the good of the prisoner may ultimately be more beneficial for hims than those projects which have specific therapeutig goals.

\section{References}

Alexander, Susan (1973). The Captive Patient: Th $\overrightarrow{5}$ Treatment of Health Problems in American Prisons 3 Washington D.C.: The American Bar Association? American Bar Association Resource Center oro Correctional Law and Legal Services (1973). Medicail and Health Care in Fails, Prisons and Other Correc $\overline{3}$ tional Facilities. A Compilation of Standards and Materials. Washington D.C.: The American Bar Association.

American Correctional Association (1969). Manual of Correctional Standards, College Park, Maryland? The American Correctional Association.

American Correctional Association (1972). Protocol fors Medical Experimentation and Pharmaceutical Testing College Park, Maryland: The American Correc $\overline{\bar{N}}$ tional Association.

American Medical Centre for Health Services Research and Development (1973). Medical Care irR U.S. Fails - a 1972 AMA Survey, Chicago: Then American Medical Association.

Bowers, J (1972). Medical research in prisons. Clearinge house Review, Chicago, 5, 148-153.

Carter, Robert M, McGee, Richard A, and Nelson, E? Kim (1975). Corrections in America, II2-I13, Newo York: J. B. Lippincott Company.

Fox, V (1972). Introduction to Corrections, 191, Engle wood-Cliffs, New Jersey: Prentice-Hall.

Jones, A D (1975). The Dangerousness of Imprisonment, 9 Ann Arbor, Michigan: Xerox University Micro films.

Jonsen, A R (1975). Bio-Medical Experimentation or: 
Prisoners: Review of Practices and Problems and Proposal of a New Regulatory Approach, San Francisco, California: University of California School of Medicine.

Kassirer, Lynn B (1974). The right to treatment and the right to refuse treatment-recent case law. Fournal of Psychiatry and Law, 2, 455-470.

Kennedy, Edward M (1972), address to the United States Senate, Congressional Record, II8, number I2I.

Merton, Robert K (1973). The Sociology of Science, 72-73, Chicago: The University of Chicago Press.

Meyer, P B (1975). Medical Experimentation on Prisoners: Some Economic Considerations, Washington D.C.: The American Bar Association.

Mitford, Jessica (1973). Kind and Usual Punishment, New York: Alfred A. Knopf.

Murton, Tom (1974). Prison doctors. Humanist, 31, 24-29.
National Sheriffs' Association (1970), Manual of Fail Administration, Washington D.C.: National Sheriffs' Association.

Schwitzgebel, Ralph K. (1968). Ethical problems in experimentation with offenders. American fournal of Orthopsychiatry, 38.

Todd, W G (I975). Non-therapeutic prison research: An analysis of potential legal remedies. Albany Laro Revierv, 39.

Unsigned article (1974), Medicine behind bars. $M D$, I8, 59-6r.

US Law Enforcement Assistance Administration and US Bureau of the Census (1973). Local fails, Washington D.C.: US Government Printing Office.

Wells, Stephen H, Kennedy, Patricia M, Kenny, John, Rezinkoff, Marvin, and Sheard, Michael H (r975). Pharmacological Testing in a Correctional Institution, Springfield Illinois: C. C. Thomas. 